\title{
FUNDAMENTOS ONTOLÓGICOS DO ATO DE AVALIAR NO CONTEXTO DO CAPITALISMO EM CRISE ${ }^{1}$
}

\author{
Frederico Jorge Ferreira Costa ${ }^{2}$
}

\begin{abstract}
Resumo:
$\mathrm{O}$ artigo evidencia os pressupostos ontológicos que fundamentam o ato de avaliar submetido às necessidades da avaliação nos marcos do capital. Trata-se de ensaio de natureza teórica, inspirado na tradição metodológica do marxismo histórico e dialético. Recorremos às obras de Marx (2015); Marx e Engels (2007, 2013); Lukács (2012, 2013); Mészáros (2002), dentre outros e de estudiosos da área de avaliação. A pesquisa permitiu compreender que o ato de avaliar tem sua origem ontológica no trabalho e que, em sociedades de classes, a avaliação pode configurar-se como distorcida e alienada. As políticas avaliativas num contexto de "Estado avaliador" e "governo empresarial", são norteadas pelo accountability. O controle crescente dos resultados, ajusta-se à lógica do capital sustentada na competição e na meritocracia. Assim, a avaliação contribui ativamente para a formação de um indivíduo adequado às novas exigências de produção e reprodução do capitalismo.
\end{abstract}

Palavras-chave: Fundamentos ontológicos da avaliação. Capitalismo em crise. Estado Avaliador.

\section{ONTOLOGICAL GROUNDS OF ASSESSING IN THE CONTEXT OF CRISIS CAPITALISM}

\begin{abstract}
:
The article highlights the ontological assumptions that underlie the act of evaluating submitted to the needs of the evaluation in the capital milestones. It is an essay of a theoretical nature, inspired by the methodological tradition of historical and dialectical Marxism. We have recourse to the works of Marx (2015); Marx and Engels (2007, 2013); Lukács (2012, 2013); Mészáros (2002), among others and of scholars in the evaluation area. The research allowed to understand that the act of evaluating has its ontological origin in the work and that, in class societies, the evaluation can be configured as distorted and alienated. Evaluative policies in a context of "evaluating state" and "corporate governance", are guided by accountability. The increasing control of results fits the logic of capital sustained in competition and meritocracy. Thus, evaluation actively contributes to the formation of an individual fit for the new demands of production and reproduction of capitalism.
\end{abstract}

Keywords: Ontological foundations of evaluation. Capitalism in crisis. State Assessor. Accountability.

\section{Introdução}

$\mathrm{O}$ ato de avaliar enquanto componente fundamental do processo educativo tem sido objeto de inúmeras polêmicas, sendo alçado, muitas vezes, à condição de prática vital a este processo, assim como objeto de questionamentos quanto a sua necessidade e função. Do mesmo modo, a avaliação é objeto de sentimentos contraditórios: de temor e ódio, por parte

1 In memoriam de Maria do Socorro Silva Lima (1970-2019), desbravadora da temática da avaliação utilizando os recursos teóricos do materialismo histórico.

2 Doutor em Educação. Professor da Faculdade de Educação de Itapipoca da Universidade Estadual do Ceará (FACEDI/UECE). Pesquisador colaborador do Instituto de Estudos e Pesquisas do Movimento Operário (IMO). Membro do Programa de Pós-graduação em Educação (PPGE/UECE) e do Mestrado Acadêmico em Serviço Social, Trabalho e Questão Social (MASS/UECE). Coordenador do Grupo de Pesquisas Ontologia do Ser Social, História, Educação e Emancipação Humana (GPOSSHE). E-mail: frederico.costa@uece.br 
de uns, a julgamento justo e necessário, por parte de outros. É particularmente interessante a sobrevalorização da visão gnosiológica do ato de avaliar, alçado, muitas vezes, a uma técnica racional e neutra capaz de validar ou não todo o processo educativo. Nesse sentido, o debate tem gravitado mais em função do modus operandi do ato avaliativo, sua forma, do que acerca de sua verdadeira natureza, origem, função e necessidade.

Nos limites desse texto, é oportuno destacar a existência de três níveis integrados de avaliação da qualidade de ensino: avaliação em larga escala em redes de ensino, realizada no país, estado ou município; avaliação institucional da escola, feita em cada escola pelo seu coletivo, e a avaliação da aprendizagem em sala de aula, realizada pelo professor (FREITAS, 2014). Esse complexo está inserido em um modelo social, uma vez que se materializa no âmbito das políticas públicas e no "chão da escola" não como uma atividade desinteressada, mas como uma atividade intencional e comprometida com o balizamento da sociedade do conhecimento. Com isso, não queremos dizer que, no cerne de uma sociedade conservadora e excludente "e no contexto de uma pedagogia autoritária, não surjam os elementos contraditórios e antagônicos que vão possibilitar a sua transformação” (LUCKESI, 2011, p. 90).

Outra variante a ser levada em consideração em relação à avaliação educacional são as tendências pedagógicas, pois delas emergem as relações que se dão no cotidiano escolar. Logo, exigem práticas diferentes de avaliação da aprendizagem. Para Libâneo (1984), existem dois grupos de pedagogias: no primeiro grupo, estão as pedagogias liberais denominadas Tendência liberal tradicional (avaliação tem a função de medição do conteúdo e utilização da testagem); Tendência liberal renovada progressiva (avaliação cumulativa e qualitativa, ênfase nos aspectos sociais e afetivos, valorização da autoavaliação); Tendência liberal renovada não-direta (ênfase na autoavaliação) e a Tendência liberal tecnicista (avaliação subordinada aos objetivos operacionalizados e à avaliação diagnóstica, formativa e somativa realizadas de forma linear e fragmentada). No segundo grupo, encontram-se as pedagogias progressistas denominadas: Tendência progressista libertária (autoavaliação considerando-se o progresso do grupo em função da prática vivenciada entre educador e educando) e a Tendência Progressista Crítico-Social dos Conteúdos (as modalidades de avaliação são realizadas de forma interativa, sendo aplicada numa perspectiva diagnóstica, continuada e participativa). O primeiro grupo estaria preocupado em estabelecer a reprodução e a conservação da sociedade, enquanto o segundo estaria voltado para as perspectivas e possibilidades de transformação social.

\begin{tabular}{|c|c|c|c|c|}
\hline Rovista Dialectus & Ano 9 & n. 16 & Janeiro-Abril 2020 & p. $82-99$ \\
\hline
\end{tabular}


Por conta do corolário dessas tendências, sabe-se que a avaliação, em seu campo conceitual, sofreu algumas mudanças históricas evidenciando, assim, a existência de algumas gerações teóricas ou perspectivas (GUBA; LINCOLN, 1989). Para a primeira geração de teóricos, a avaliação era tida como sinônimo de medida. Esse período, compreendido entre 1900 e 1930, ficou conhecido como a Idade da Eficiência e dos Testes, foi influenciado pelas ideias do engenheiro americano Frederick Taylor (1856-1915), incidindo sobre os sistemas educacionais. Em termos práticos, a avaliação como medida em sala de aula significou uma perspectiva que se reduzia a administração de um ou mais testes em determinados períodos e tinha como função classificar, selecionar e certificar a aprendizagem.

Para a segunda geração, a avaliação era compreendida como sinônimo de descrição da aprendizagem por não se limitar somente a medir o conhecimento do aluno, como propunha a geração anterior, mas tinha como meta determinar até que ponto os alunos teriam atingido os objetivos definidos. Nesta geração, entretanto, a função reguladora fazia-se presente, além de persistirem também certas características da avaliação da geração anterior. Nesse período, entre 1930 e 1940, Ralph Tyler, um pesquisador e avaliador americano, inaugurou a necessidade de formular objetivos de ensino e aprendizagem para definir mais concretamente o que se estava avaliando. O processo de cumprimento ou não desses objetivos foi denominado de avaliação educacional. Por conta de suas contribuições, Tyler é referido como o pai da avaliação educacional.

A terceira geração foi designada como a geração dos formuladores de juízos de valor acerca das aprendizagens, do sistema educacional ou de qualquer outro objeto a ser avaliado. Mantida a função técnica e descritiva das gerações anteriores, os avaliadores desempenhavam a função de juízes. Foi uma época de sofisticação teórica e desenvolvimento da avaliação, período entre 1958 e 1972. Nesse mesmo período, surgiu o conceito de avaliação somativa, relacionada à prestação de contas, certificação e seleção; bem como o conceito de avaliação formativa, mais associada ao desenvolvimento, à melhoria e regulação dos processos de ensino e de aprendizagem.

Guba e Lincoln (1989) propõem uma quarta geração de avaliação denominada negociação e construção da aprendizagem que se caracterizaria por não estabelecer quaisquer parâmetros de princípios, pois estes seriam definidos em um processo de negociação e interatividade com os sujeitos envolvidos. Tal perspectiva baseia-se em algumas concepções fundamentais, tais como: os professores devem partilhar o poder de avaliar entre os alunos; a avaliação e o processo ensino e aprendizagem interagem; a avaliação formativa tem como

\begin{tabular}{|c|c|c|c|c|}
\hline Rovista Dialectus & Ano 9 & n. 16 & Janeiro-Abril 2020 & p. $82-99$ \\
\hline
\end{tabular}


função principal a melhoraria e regulação das aprendizagens, modalidade privilegiada; a avaliação deve servir para ajudar a desenvolver as aprendizagens das pessoas em detrimento do julgamento e da classificação; a avaliação é uma construção social, pois concebe os contextos, os processos e as negociações entre os envolvidos, constrói conhecimentos e considera os processos cognitivos, sociais e culturais da sala de aula.

Concepções tecnocráticas de educação, como aquela derivada da aplicação da análise experimental do comportamento à educação (PEREIRA; MARINOTTI; LUNA, 2004), têm descrito o processo educativo como um sistema de meios; o ensino como caminho para se obter um fim, a aprendizagem do aluno, e a ser validado pelo ato avaliativo, de preferência contínuo e progressivo. Concepções construtivistas, em particular, como a de Piaget (2000) têm questionado tal perspectiva por sobrevalorizarem os resultados e não o processo de aprendizagem e a ampliação dos esquemas cognitivos. Já uma terceira linha de argumentação, presente no debate educacional, questiona a subvalorização do contexto social mais amplo no próprio ato de ensinar e aprender.

Apesar dessa diversidade de posicionamentos, na cultura escolar contemporânea marcada pelo capitalismo em crise, a avaliação tem sido alçada constantemente à posição central. É forçosa a tentativa de demonstrar e provar a pertinência ou não do processo educativo, de modo que o sujeito da aprendizagem passa a ver na avaliação o momento da prova, o verdadeiro "ritual de passagem" que lhe confirma como aquele que adquiriu um novo saber. Tal processo não só pode levar a importantes estratégias de controle e submissão escolar (DEAKON; PARKER, 2000), como parece igualar todo o processo educativo ao ato avaliatório: o sujeito é o resultado de sua avaliação.

Nessa esteira, quase que naturalizada no espaço escolar e em outros espaços educativos, pouco se tem pensado e discutido sobre a origem do ato avaliativo e sua função social; menor ainda é o debate acerca da raiz ontológica do ato de avaliar. Embora a avaliação esteja em toda parte, pois o ato de escolher, julgar, discriminar, entre outros atos avaliatórios, diz da especificidade do ser social, a avaliação tem sido posta como atividade altamente especializada e técnica, apartada da sociabilidade em geral, condição básica de sua suposta confiabilidade. No entanto, uma simples alusão ao significado epistemológico da palavra encaminha a sua origem: avaliar é um ato de valoração, busca de uma medida de valor para o ato social. Sua origem, portanto, diz respeito aos processos vitais do ser humano, como trabalhar, pensar e se comunicar. 
Eis um primeiro movimento que se pretende encetar aqui: descrever e demonstrar a importância do ato de avaliar como componente fundamental do ato de trabalhar, ato constitutivo do ser humano como ser intencionalmente diferenciado do ser animal, orgânico, denominado ser social, uma vez que produz e reproduz pelo trabalho a cultura humana (LUKÁCS, 2013).

Trata-se de ensaio de natureza teórica inspirado na tradição metodológica do marxismo histórico e dialético, com objetivos mais descritivos e exploratórios, visando contribuir com novos pontos de vista sobre essa importante temática. Para tanto, nos apoiaremos numa revisão narrativa da literatura de autores da tradição marxista e crítica em um diálogo com diversos outros teóricos consagrados na área da avaliação. A pertinência de tal debate se agiganta no momento em que não só a educação parece estar em crise, mas a própria sociabilidade humana sob a égide do capital.

\section{Lugar do ato de avaliar no trabalho: fundamento do ser social}

A palavra avaliação, em seu aspecto epistemológico, tem origem na língua latina, na composição a-valere que significa "dar valor a", isto é, corresponde ao ato de julgar, de emitir um juízo de valor a partir de normas e padrões socialmente válidos, uma escolha dentre alternativas, cujo fundamento é a capacidade e a liberdade humana de escolher entre alternativas. Para Luckesi (1995, p. 33), a avaliação é “um julgamento de valor sobre manifestações relevantes da realidade, tendo em vista uma tomada de decisão", especialmente quando tal realidade demanda tais resoluções.

Nesse sentido, ao explorar esta questão, optamos pela perspectiva ontológica inaugurada por Karl Marx, já que, de acordo com Lukács (2012, p. 25, grifos nossos), "Ninguém se ocupou tão extensamente quanto Marx com a ontologia do ser social". Nesta perspectiva, devemos mergulhar nas raízes dos fenômenos tipicamente humanos em busca de indícios e fundamentos da atividade avaliativa enquanto marca singular do homem? Ou ainda, se trabalho é o fundamento do ser socialmente humano, como ele se relaciona como os processos de julgamento e avaliação da realidade? É próprio do ser humano o ato de avaliar?

De acordo com a paleoantropologia, nosso fundamento como espécie biológica nos conduz à África onde divergimos de nosso ancestral comum como os chimpanzés há aproximadamente sete milhões de anos (COYNE, 2014). Tal evidência indica que a espécie Homo sapiens sintetiza, milhões de anos depois, dialeticamente, a unidade entre ser

\begin{tabular}{|c|c|c|c|c|}
\hline Q Rovista Dialectus & Ano 9 & n. 16 & Janeiro-Abril 2020 & p. $82-99$ \\
\hline
\end{tabular}


inorgânico, orgânico e social. Nos termos de Lukács (2010, p. 36), sem levar em consideração os problemas gerais do ser, ou seja, a inter-relação e a especificidade dos três grandes tipos de ser, "não se pode formular corretamente nenhuma das questões autenticamente ontológicas do ser social, muito menos conduzi-las a uma solução que corresponda à constituição desse ser". Nesse sentido, o autor explicita ainda que o homem pertence também à esfera do ser biológico, portanto sua existência, transcurso e fim se fundam de forma ampla nesse tipo de ser e que, concomitantemente, esta evidência implica, igualmente, em uma relação ininterrupta com o ser inorgânico e que sem a inter-relação entre essas duas esferas o ser humano não poderia, de modo algum, se desenvolver como ser social.

Tal contradição entre uma criatura vinculada a uma espécie biológica e, ao mesmo tempo, à esfera social e cultural, é algo inteiramente singular e original no universo conhecido. A reflexão teórica de Karl Marx, a nosso ver, tornou inteligível os fundamentos próprios dessa criatura, o ser humano. Em 1844, em seus estudos iniciais sobre economia política, expressos nos Manuscritos econômico-filosóficos, Marx (2015) destaca os elementos da especificidade humana frente a natureza. Para ele, fisicamente, o homem só vive dos produtos da natureza, sejam na forma de alimento, aquecimento, vestuário, habitação, etc. A universalidade do homem, então, aparece naquela que compartilha com a natureza o seu corpo inorgânico, tanto na medida em que ela é um meio de vida imediato, quanto na medida em que ela é o objeto/matéria do trabalho, a base da atividade vital decorrente da própria vida produtiva (MARX, 2015). O homem compartilha, portanto, com a natureza o corpo inorgânico e orgânico como ser animal, mas isso não quer dizer que o corpo humano está subsumido ao natural pelo que compartilha com a natureza inorgânica e orgânica: "O homem viver da natureza significa: a natureza é o seu corpo, com o qual ele tem de permanecer em constante processo para não morrer" (MARX, 2015, p. 311).

Desse modo, partindo de Marx, podemos afirmar que o homem é, antes de tudo, um ser natural, pois faz parte da natureza, seja ela inorgânica ou orgânica, mas tal realidade não resume a natureza humana, pois ela é mais ampla. Se seu corpo faz parte da natureza, ele precisa estar em constante processo com ela para não morrer e isso é importante. Se o homem não fosse um ser natural, como poderia entrar em um metabolismo constante com a natureza? Porém o homem não é só um ser natural. Ele não possui apenas um fundamento natural biológico e físico-químico. O que faz, entretanto, com que ele, mesmo sendo um ser natural, destaque-se da natureza e faça dela seu objeto? É exatamente onde reside sua universalidade, sua vida genérica e seu ser social, o trabalho enquanto atividade de mediação primeira entre o

\begin{tabular}{|c|c|c|c|c|}
\hline Rovista Dialectus & Ano 9 & n. 16 & Janeiro-Abril 2020 & p. $82-99$ \\
\hline
\end{tabular}


homem e a natureza. Assim, o trabalho, atividade posterior na evolução humana consciente e livre, constitui a atividade vital e tipicamente humana, a base de sua vida produtiva e social, que lhe permite afirmar-se como genérico, um ser que trabalha. O trabalho é a atividade responsável pela superação das condições naturais infra-humanas, engendrando as possibilidades do mundo humano, configurado na cultura.

Por isso, Marx e Engels (2007), na obra Ideologia alemã, indicam que os seres humanos para viverem precisam, antes de tudo, cumprir suas necessidades naturais de comida e bebida, para daí demandarem necessidades culturais como vestimenta, moradia, dentre outras. Seguindo a pegada de Marx, concluiríamos que o primeiro ato propriamente histórico do homem é aquele que garante a produção dos meios para a satisfação de suas necessidades, a produção da própria vida material e cultural. Este é, sem dúvida, um ato histórico, uma condição fundamental de toda a história, pois sem a teleologia inaugurada pelo trabalho o homem não teria como se apresentar como ser histórico, capaz de projetar seu passado e presente em uma condição futura. Ainda hoje, assim como há milênios, as necessidades humanas têm de ser cumpridas diariamente, a cada hora, simplesmente para manter os homens vivos. Agora, não se trata apenas da mera condição objetiva da sobrevivência humana; trata-se da base sobre a qual se projetou um ser social que não é simplesmente natural, mas que trabalha, produz instrumentos, tem consciência, linguagem e cultura.

Em sua obra de maturidade, O capital - crítica da economia política, Marx (2013, p 255-256) destaca o caráter fundante do trabalho em relação ao ser social numa citação que se tornou clássica. Embora já amplamente analisada e discutida, apresentaremos a citação literal a fim de destacar alguns aspectos centrais para discutir a importância constitutiva do ato de avaliar enquanto atividade coetânea ao ato de trabalhar:

O trabalho é, antes de tudo, um processo entre o homem e a natureza, processo este em que o homem, por sua própria ação, medeia, regula e controla seu metabolismo com a natureza. Ele se confronta com a matéria natural como com uma potência natural [Naturmacht]. A fim de se apropriar da matéria natural de uma forma útil para sua própria vida, ele põe em movimento as forças naturais pertencentes a sua corporeidade: seus braços e pernas, cabeça e mãos. Agindo sobre a natureza externa e modificando-a por meio desse movimento, ele modifica, ao mesmo tempo, sua própria natureza. Ele desenvolve as potências que nela jazem latentes e submete o jogo de suas forças a seu próprio domínio. Não se trata, aqui, das primeiras formas instintivas, animalescas [tierartig], do trabalho. Um incomensurável intervalo de tempo separa o estágio em que o trabalhador se apresenta no mercado como vendedor de sua própria força de trabalho daquele em que o trabalho humano ainda não se desvencilhou de sua forma instintiva. Pressupomos o trabalho numa forma em que ele diz respeito unicamente ao homem. Uma aranha executa operações semelhantes às do tecelão, e uma abelha envergonha muitos arquitetos com a

\begin{tabular}{|l|c|c|c|c|}
\hline Rovista & Ano 9 & n. 16 & Janeiro - Abril 2020 & p. $82-99$ \\
\hline
\end{tabular}


estrutura de sua colmeia. Porém, o que desde o início distingue o pior arquiteto da melhor abelha é o fato de que o primeiro tem a colmeia em sua mente antes de construí-la com a cera. No final do processo de trabalho, chega-se a um resultado que já estava presente na representação do trabalhador no início do processo, portanto, um resultado que já existia idealmente. Isso não significa que ele se limite a uma alteração da forma do elemento natural; ele realiza neste último, ao mesmo tempo, seu objetivo, que ele sabe que determina, como lei, o tipo e o modo de sua atividade e ao qual ele tem de subordinar sua vontade. E essa subordinação não é um ato isolado. Além do esforço dos órgãos que trabalham, a atividade laboral exige a vontade orientada a um fim, que se manifesta como atenção do trabalhador durante a realização de sua tarefa, e isso tanto mais quanto menos esse trabalho, pelo seu próprio conteúdo e pelo modo de sua execução, atrai o trabalhador, portanto, quanto menos este último usufrui dele como jogo de suas próprias forças físicas e mentais. (MARX, 2013, p 255-256).

Numa análise desse texto, direto, mas extremamente complexo, podemos indicar alguns elementos importantes para a problemática do processo avaliativo. Primeiro, o trabalho é um processo entre o homem e a natureza (embora não se resuma a isso, esse é seu aspecto fundamental, pois aí sua natureza é também modificada), mas não é um processo qualquer, como o que ocorre entre os outros seres biológicos e o meio natural ou, até mesmo, um homem ainda como ser instintivo e animal (trabalho em suas formas instintivas, ainda infrahumanas). A diferença está no próprio processo de trabalho do homem que, por sua própria ação, medeia, regula e controla seu metabolismo com a natureza. Segundo, quando o ser humano age sobre a natureza externa modificando-a por meio desse movimento, ele modifica, ao mesmo tempo, sua própria natureza, ou seja, ao transformar o mundo natural, o homem transforma-se como ser social. O ser humano, então, se efetiva, forma-se e se autocria por meio de sua própria atividade, ele não apenas se reproduz, mas produz algo novo neste processo e o incorpora a sua natureza.

Desse modo, quando ele desenvolve as potências que estão latentes na natureza, submetendo-as ao jogo de suas forças e a seu próprio domínio, simultaneamente, ele produz, desenvolve e descobre novas habilidades, conhecimentos e valores a partir de potências que nele jazem latentes que viabilizam, no futuro, processos tais como o uso de conhecimentos, linguagem, valores, entre outros, numa atividade diferenciada chamada trabalho e ausente do mundo animal. Nesse sentido, o trabalho é a origem da formação propriamente humana e gera a necessidade futura da educação como prática social.

Um terceiro aspecto a destacar: no final do processo de trabalho, chega-se a um resultado que já estava presente na mente do ser humano no início do processo, portanto um resultado que já existia idealmente. Aqui não há uma simples alteração da forma do elemento natural, pois os demais seres biológicos - de uma ameba a um elefante - também alteram o

\begin{tabular}{|l|l|l|l|l|}
\hline Rovista Dialectus & Ano 9 & n. 16 & Janeiro-Abril 2020 & p. 82 - 99 \\
\hline
\end{tabular}


ambiente natural, porém transformam a natureza a partir de uma intencionalidade meramente biológica. Nesse sentido, Lukács (2013) faz uma distinção esclarecedora entre causalidade natural e teleologia humana: os objetivos ou intenções no mundo natural são fixos e causalmente produzidos segundo certas leis naturais inscritas no mundo inorgânico e no código genético do animal. No entanto, a teleologia humana tornou exponenciais as possibilidades agenciadas pelo trabalho, viabilizando intenções especificamente humanas, mesmo que condicionadas, em certo grau, a sua base natural.

De fato, no processo de trabalho, o homem realiza no elemento natural seu objetivo que ele sabe que determina, como lei, o tipo e o modo de atividade a qual ele tem de subordinar sua vontade. Nessa atividade produtiva, o indivíduo, a fim de se apropriar da matéria natural de uma forma útil para sua própria vida, põe em movimento as forças naturais pertencentes a sua corporeidade: seus braços e pernas, cabeça e mãos. Para chegar ao fim desejado, num jogo de forças físicas e mentais, o domínio das forças naturais exige, mesmo que inconscientemente, certo conhecimento da legalidade da natureza, um conjunto de habilidades para colocar os elementos naturais sob o controle de seus objetivos e uma determinada capacidade de avaliar - baseada na valorização de elementos positivos ou negativos para a realização dos objetivos postos pela prévia ideação. Esse procedimento avaliativo também norteia o esforço dos órgãos que trabalham, já que o processo de trabalho exige a vontade orientada a um fim que se manifesta como atenção do trabalhador durante a realização de sua tarefa; esta exige avaliação constante no processo de trabalho, como também dos seus resultados. A utilidade ou não de qualquer objetivação surgida no processo de trabalho é, em si, um procedimento avaliativo. Em síntese, na atividade fundante da sociabilidade humana - o trabalho - estão presentes procedimentos avaliatórios e valorativos. Logo, podemos afirmar, a partir de Marx, que o ato de avaliar tem sua origem ontológica no trabalho, a atividade vital humana, que criou o ser social genericamente humano.

Como podemos conduzir tal discussão para a realidade da educação e da escolarização? No nosso entendimento, os processos avaliativos de rendimento escolar, por exemplo, comportam intrinsecamente uma base ontológica que não pode ser eliminada, pois não existe atividade humana em que não exista valoração. A avaliação é imanente ao ser social, pois está inserida no ato fundante do tornar-se humano, o ato de trabalho.

Segundo Lukács (2012, p. 44), no "trabalho estão contidas in nuce todas as determinações que [...] constituem a essência do novo no ser social. Desse modo, o trabalho pode ser considerado o fenômeno originário, o modelo do ser social". Além disso, é através

\begin{tabular}{|l|l|l|l|l|}
\hline Qonista Dialectus & Ano 9 & n. 16 & Janeiro-Abril 2020 & p. 82 - 99 \\
\hline
\end{tabular}


da categoria do trabalho que se realiza, no âmbito do ser material, um pôr teleológico para além da causalidade natural, dando surgimento a uma nova objetividade. Esse fato ontológico é fundante do ser social propriamente humano, pois "é capaz de trazer à vida processos causais, modificar processos, objetos etc. do ser que normalmente só funcionam espontaneamente, e transformar entes em objetividades que sequer existiam antes do trabalho" (LUKÁCS, 2010, p. 43-44). Para isso ocorrer, o sujeito que trabalha necessita partir de fatos corretamente reconhecidos no sentido prático, segundo sua causalidade natural e potencialidade humana, bem como avaliá-los devidamente.

Essa avaliação baseia-se na dialética entre fins e meios postos pela consciência (LUKÁCS, 2013). Posto um fim (a produção de um machado ou a construção de uma usina nuclear) surge a busca dos meios, que pressupõe algum conhecimento do real. Quais os melhores materiais? Onde os encontrar? Como os transportar? Quais procedimentos a seguir? Como fazer? Como poupar tempo, energia e trabalho? São questões que implicam alternativas objetivas e escolhas subjetivas. Mas, só há escolha, se há valoração. Esse material é inútil; aquele procedimento poupa mais tempo do que este; tal instrumento é frágil; o custo social do transporte não compensa a busca de determinados materiais, dentre outras possibilidades. Tudo isso envolve, em última instância, o ato de avaliar presente no processo em que um projeto ideal alcança sua realização material, isto é, o pôr idealizado de um determinado fim transforma a realidade material, inserindo nela algo e fazendo surgir, nesse confronto com a natureza, algo qualitativamente e radicalmente novo. O critério de avaliação - certo ou errado, útil ou inútil - tem como referência a finalidade de todos os processos citados: um machado eficiente ou uma usina nuclear segura (LUKÁCS, 2010; 2012; LESSA, 2012; ZANARDINE, 2008).

Como o trabalho também é o modelo de toda práxis social propriamente humana, podemos concluir que o ato de avaliar faz-se presente no conjunto da vida social dos homens. Assim como o trabalho torna-se trabalho explorado e alienado nas sociedades divididas em classes sociais, o ato de avaliação pode configurar-se como distorcido e alienado. Bem como o trabalho, porém, o ato de avaliar é inseparável da própria existência do ser social.

\section{A educação como momento da reprodução social: o ato de avaliar}

A realidade social humana não se reduz ao trabalho, isto é, ao metabolismo orientado teleologicamente entre o ser humano e a natureza. Existem inúmeras atividades

\begin{tabular}{|l|c|c|c|c|}
\hline Qovista Dialectus & Ano 9 & n. 16 & Janeiro-Abril 2020 & p. 82 - 99 \\
\hline
\end{tabular}


humanas que não se vinculam imediatamente com a natureza, como a arte, a política e a educação. Nesse sentido, diz Tonet (2013) que o ato educativo configura uma relação entre um sujeito e um objeto que é, ao mesmo tempo, um sujeito. É uma atividade que incide sobre a consciência do outro, tendo em vista induzi-la a pensar e agir de determinada maneira. No ato educativo de quem ensina, o conjunto dos conhecimentos e habilidades necessários para obtenção dos fins propostos está longe de garantir a consecução do objetivo, pois não é possível prever a reação do educando.

Nessa perspectiva, inspirada em Lukács (2013), a educação, no sentido ontológico, é um tipo específico de práxis social integrante do complexo da reprodução social. Ela é essencial, pois não existe sociedade humana sem educação. Por meio dela, os indivíduos apropriam-se das objetivações produzidas pela atividade coletiva de todos, condição fundamental para produzir outros tipos de objetivações. Assim, a sociedade humana reproduzse, modifica-se e se desenvolve. De acordo com Márkus (2015, p. 33):

\footnotetext{
[...] pelo fato de que o homem vive em um mundo humanizado, em que as habilidades e as necessidades humanas, desenvolvidas no passado, confrontam-no desde o seu nascimento em uma materialidade pronta, ele tem à sua disposição, nesta forma presente objetivada, os resultados de todo o desenvolvimento social anterior. É apenas por causa de tudo isso que ele não necessita avançar do zero, mas somente continuar esse desenvolvimento a partir do ponto deixado pelas gerações anteriores. No processo de "apropriação" [...] de objetos humanizados (o que constitui uma das principais dimensões de socialização), o indivíduo transforma em necessidades e competências da vida pessoal as carências e habilidades historicamente criadas e objetivadas nos elementos do seu meio - e, desta forma, uma transmissão prático-material da tradição é realizada na sociedade, o que constitui a base da continuidade histórica e, ao mesmo tempo, torna possível o progresso social.
}

Dessa maneira, a continuidade da sociedade, isto é a reprodução social, exige um tipo de mediação responsável pela apropriação por parte dos indivíduos de objetos humanizados resultantes do trabalho e de outras práxis sociais (uso de diversas habilidades, técnicas, linguagem, conhecimentos, tradições). Então, devido à descontinuidade entre o que é produzido coletivamente pela humanidade (gênero humano) e os indivíduos, principalmente nas sociedades divididas em classes sociais, a reprodução do ser social exige uma mediação entre gênero humano e indivíduos concretos, que, numa dialética de transmissão e apropriação, processe a continuidade do ser social de geração a geração. Essa mediação é a educação e está ligada à formação da individualidade humana, base do ser social humano, pois o sujeito que aprende é, ao mesmo tempo, um sujeito coletivo e singular.

\begin{tabular}{|l|l|l|l|l|}
\hline Qenista Dialectus & Ano 9 & n. 16 & Janeiro-Abril 2020 & p. 82 - 99 \\
\hline
\end{tabular}


Dessa forma, segundo Duarte (1999), a ação educativa está sempre orientada a um ser humano singular (o educando) e é dirigida por outro ser humano singular (o educador) e se realiza sempre em condições materiais e não-materiais singulares. Essa singularidade não é fruto, porém, de uma existência independente da história social. O caráter da cultura e da reprodução social decorrentes do ato de trabalho tem como característica fundamental ser um processo plástico e aberto, o que garante a possibilidade do novo, do histórico e do singular até mesmo no próprio ato reprodutivo. Portanto, a formação do ser humano é um processo que sintetiza dialeticamente um conjunto de elementos produzidos pela história humana enquanto ato coletivo e singular.

Além dessa determinação, há outra indicada por Lukács (2013, p. 178), quando afirma: “a problemática da educação remete ao problema sobre o qual está fundada: sua essência consiste em influenciar os homens no sentido de reagirem a novas alternativas de vida do modo socialmente intencionado". Esse modo socialmente desejado é determinado, em última instância, pela forma como a sociedade é dinamicamente organizada, portanto, ele não é congelado no tempo:

Toda sociedade reivindica certa quantidade de conhecimentos, habilidades, comportamentos etc. de seus membros; o conteúdo, o método, a duração etc. da educação no sentido mais estrito são as consequências das carências sociais daí surgidas. Naturalmente, se essas circunstâncias assim modificadas durarem o tempo suficiente, elas terão certos efeitos sobre a constituição física e psíquica dos homens. (LUKÁCS, 2013, p. 177).

Assim, a práxis educativa busca mediar o processo de apropriação por parte dos indivíduos da experiência humana acumulada (objetivações) e, ao mesmo tempo, intenta produzir individualidades de acordo com as exigências de determinado tipo de sociedade. A educação age influenciando o campo das decisões individuais, o que orienta o processo de apropriação por parte dos indivíduos da experiência humana acumulada. A formação de individualidades compatíveis com um tipo de sociedade concreta é, então, o que condiciona o processo de transmissão e apropriação do conjunto de objetivações mínimas para a continuidade de cada sociedade. Cada tipo específico de sociedade precisa de um indivíduo concreto compatível com ela, no entanto tal função não resume o processo educativo, visto que a educação pode produzir sujeitos produtores de educação, cultura e novas formas de produzir riqueza e agir sobre a natureza para além do que prevê a ideologia social.

\begin{tabular}{|l|l|l|l|l|}
\hline Qevista Dialectus & Ano 9 & n. 16 & Janeiro-Abril 2020 & p. 82 - 99 \\
\hline
\end{tabular}


No capitalismo, manifesta-se a escola dual, sob o disfarce de uma escola única: uma para as camadas dominantes e outra para os trabalhadores, uma para formar dirigentes e outra para preparar mão de obra para a acumulação de capital, ambas orientadas por valores e procedimentos educacionais centrados na competição, no individualismo e na cidadania formal. Logo, é o horizonte de uma sociedade dada e de sua reprodução que orienta e condiciona o critério avaliativo dos processos educacionais historicamente postos que estão na base da formação dos indivíduos.

\section{Avaliação educacional no contexto do capitalismo em crise}

Para entender a realidade em que estamos inseridos, precisamos compreender o modo como os seres humanos produzem sua própria existência sob a lógica do capital. Conceber o ato de avaliar no contexto das políticas públicas educacionais impostas por organismos internacionais remete-nos, necessariamente, por uma série de mediações, à análise, mesmo aproximativa, da estrutura do capitalismo; pois, nos últimos anos são as perspectivas econômicas que permeiam o debate no campo da avaliação e explicam seu forte impacto no meio educacional.

Como afirma Nóvoa (2009), os estudos internacionais de avaliação conduzidos pela International Association for the Evaluation of educational Achievement (IEA) ou pela Organização para a Cooperação e o Desenvolvimento Econômico (OCDE) têm como principal referência a qualificação dos recursos humanos e sua importância para o desenvolvimento econômico e social. Podemos levar em consideração que, a partir desses objetivos, concretizam-se as práticas avaliativas que, para serem compreendidas, precisam considerar o contexto histórico, político, econômico em que estão inseridas. Por exemplo, categorias como capital variável ou queda tendencial da taxa de lucro, embora pareçam abstratas ou amplas demais, condicionam a lógica presente nas políticas que orientam os processos avaliativos no cotidiano da escola pública. Não é oportuno discutir toda a lógica de funcionamento do capitalismo para se chegar à avaliação no contexto da crise atual do capital, pois nos desviaria do objetivo central da análise, no entanto é nesse universo social regido pelo capital que se situa o ato de avaliar na educação.

Em nosso percurso teórico, portanto, procuramos entender tanto a ontologia do ato de avaliar como os pressupostos ontológicos que fundamentam o ato de avaliar submetido às necessidades da avaliação nos marcos do capital. Como vimos, o ato de avaliar é imanente

\begin{tabular}{|c|c|c|c|c|}
\hline Rovista Dialectus & Ano 9 & n. 16 & Janeiro-Abril 2020 & p. $82-99$ \\
\hline
\end{tabular}


à atividade humana, sendo seus critérios e conteúdos determinados pelas formas de funcionamento de cada sociedade. No caso específico da educação, a avaliação vincula-se à tipicidade social esperada e aos modelos organizativos de determinadas formas sociais. Então, o capitalismo, como sistema totalizante, exige, em última instância, que a avaliação educacional viabilize em seus marcos a reprodução das condições de existência do capital.

A educação, em seu aspecto reprodutor, põe e repõe a formação constante de possíveis vendedores e compradores de força de trabalho, além de inúmeras atividades mediadoras de relação fundamental no capitalismo. Faz isso, em sentido amplo, na reprodução das condições ideológicas existentes e, em sentido restrito, por meio da organização escolar, do currículo, da formação docente, das práticas didáticas, da estrutura de avaliação, dos programas de livros didáticos, das políticas educacionais e do tipo de gestão, que tem em vista um modelo de ser humano necessário à sociedade atual. Mas, não é só isso. O capitalismo como sistema totalizante imprime sua forma de ser em cada detalhe dos complexos sociais que compõem cada formação social específica em cada país e nação.

Um bom exemplo disso é a escola dual: ela naturaliza hierarquias nas estruturas educacionais, os modelos de gestão, os padrões avaliativos, o tempo pedagógico, os discursos educacionais de acordo com a classe social a que se destina. Tais processos aparecem como coisas cristalizadas em sua forma de ser, mas respondem aos ritmos e formas dos processos de produção do capital.

\section{Considerações finais}

Até aqui, apresentamos três determinações importantes, da mais abstrata a mais concreta, que possibilitam a compreensão da avaliação educacional nos tempos atuais. A primeira afirmou que não há atividade humana sem valoração, pois, o metabolismo entre ser humano e natureza, que funda a sociedade e garante sua existência, tem em sua estrutura o ato de avaliar. A segunda explicou que a educação, momento essencial da reprodução social e práxis que possui como modelo o ato de trabalho, tem como parâmetro de sua ação o processo avaliativo para garantir sua eficácia segundo cada tipo concreto de sociedade. E a terceira alegou: o capitalismo é a forma social que, na atualidade, dá sentido ao funcionamento das relações entre os seres humanos e natureza e, entre si mesmos. O conceito de capitalismo, nessa perspectiva, abarca um processo totalizante que vai da esfera econômica e social, relacionada à estrutura básica da sociedade, ao campo da cultura, compreendendo a vida

\begin{tabular}{|l|l|l|l|l|}
\hline Rovista Dialectus & Ano 9 & n. 16 & Janeiro-Abril 2020 & p. 82 - 99 \\
\hline
\end{tabular}


cotidiana e mentalidade diária, as normas morais e os modelos éticos, as formas de consciência religiosa, as artes e as ciências. Portanto, estão presentes na concretude do capitalismo o metabolismo entre homens e natureza (trabalho) e o processo de reprodução social (com destaque para a educação).

$\mathrm{O}$ ato de avaliar e o processo reprodutivo social que ocorre por meio da instituição escolar, estão, no contexto do capitalismo, subordinados à lógica do capital. Assim, como o valor de uso é o veículo do valor de troca, isto é, o que importa é o que é vendível, independentemente se é saudável ou não para as pessoas, ou se forma ou deforma esse ser, consideramos também, que o ato de avaliar e o processo de trabalho estão subordinados ao processo de valorização; e o conjunto das atividades sociais está submetido à produção e reprodução do capital. É claro que isso não ocorre de maneira direta, mas por meio de uma série de mediações complexas, como as políticas educacionais, em particular na sua dimensão avaliativa.

As políticas educacionais em seus aspectos avaliativos passaram a ser influenciadas, entre outros determinantes, por mudanças substantivas na forma política (Estado) de dominação do capital. As grandes ondas de privatização, desregulamentação e diminuição de impostos, que se espalharam por todo o mundo a partir dos anos 1980, reestruturam o próprio Estado: de fora, com privatizações maciças de empresas públicas que põe fím ao "Estado produtor"; de dentro, com a instauração de um Estado avaliador e regulador que mobiliza novos instrumentos de poder e, com eles, estrutura novas relações entre governo e sujeitos sociais.

Dessa forma, mecanismos econômicos capitalistas passam a submeter a ação pública para discriminar não apenas as agendas e as não agendas, mas a própria maneira de realizar as agendas. O funcionamento do Estado curva-se às regras de eficácia das empresas privadas. Há uma mercantilização da instituição pública obrigada a funcionar de acordo com as regras empresariais. O Estado passa a ser mais flexível, reativo, fundamentado no mercado e orientado ao consumidor. De fato, essa perspectiva não visa apenas a aumentar a eficácia e a reduzir os custos da ação pública; ela subverte radicalmente os fundamentos da democracia moderna, isto é, o reconhecimento de direitos sociais ligados ao status de cidadão. Passa-se a ver o Estado como uma empresa que se situa no mesmo plano das entidades privadas e sua eficácia é quantificada para ser comparada com a de outros atores. Em um sentido mais amplo, a "boa governança" é aquela que respeita as condições de gestão sob os préstimos do ajuste estrutural e, acima de tudo, aos fluxos financeiros e comerciais do mercado mundial.

\begin{tabular}{|l|l|l|l|l|}
\hline Q & Ano 9 & n. 16 & Janeiro - Abril 2020 & p. 82 - 99 \\
\hline
\end{tabular}


Por isso, os Estados nacionais, em particular os que têm uma posição subordinada na divisão internacional do trabalho como o Brasil, passam a serem controlados por um conjunto de instâncias supragovernamentais e privadas que determinam os objetivos e os meios da política que deve ser conduzida. Então são produzidos medidas e dispositivos nos diversos campos da esfera pública para favorecer as denominadas normas internacionais, isto é, interesses de grandes grupos oligopolistas internacionais. Assim, atualmente, são os imperativos, as premências e as lógicas das empresas privadas nacionais e internacionais que comandam diretamente as agendas do Estado, como o brasileiro.

É nesse contexto de "Estado avaliador" e "governo empresarial" que emerge o modo de direção baseado na responsabilidade e no autocontrole o accountability. Tal modelo de organização do processo de trabalho vem orientando a atividade docente na escola pública e, em especial, nas políticas avaliativas.

Nesse estágio de adaptação da gestão pública ao modelo empresarial e captura da subjetividade pela racionalidade técnica do capital, a avaliação torna-se não só uma forma de controle, mas um modo de se formar um indivíduo adequado às novas exigências de produção e reprodução do capitalismo.

Nesses termos, o accountability traz um modelo avaliativo próprio da esfera empresarial que se espalha para setores bem diversos como saúde, educação, assistência social e sistema judiciário. A ideologia da "técnica de si mesmo", de avaliação permanente, da instrumentalização de si mesmo e do outro, são mecanismos de bom desempenho no campo concorrencial capitalista. Não visam apenas adaptação e integração, procuram, em última instância, a intensificação do desempenho. Na esfera privada, buscam uma maior exploração do trabalho. Na esfera pública, intentam reduzir custos, por meio da precarização das condições de trabalho dos servidores públicos.

Em termos de política pública educacional, o "Estado Avaliador", baseado no currículo nacional comum e no controle crescente dos resultados, ajusta-se à lógica do capital sustentada na competição e na meritocracia.

\section{Referências}

COYNE, Jerry Allen. Por que a evolução é uma verdade. São Paulo: JSN Editora, 2014.

\begin{tabular}{|c|c|c|c|c|}
\hline Rovista Dialectus & Ano 9 & n. 16 & Janeiro - Abril 2020 & p. $82-99$ \\
\hline
\end{tabular}


DEAKON, Roger; PARKER, Ben. Educação como sujeito e como recusa. In.: SILVA, Tomaz Tadeu (Org.). O sujeito da educação: estudos foucaultianos. Rio de Janeiro: Vozes, 2000 .

DUARTE, Newton. A individualidade para-si: contribuição a uma teoria histórico-social da formação do indivíduo. 2. ed. Campinas, SP: Autores Associados, 1999.

FREITAS, Luiz Carlos de. et al. Avaliação Educacional: caminhando pela contramão. 6. ed. Petrópolis, RJ: Vozes, 2014.

GUBA, Egan.; LINCOLN, Yvonna. Fourth generation evaluation. Newbury Park: Sage Publications, 1989.

LESSA, Sergio. Mundo dos homens: trabalho e ser social. 3. ed. São Paulo: Instituto Lukács, 2012.

LUCKESI, Cipriano. C. Avaliação da aprendizagem escolar. São Paulo: Cortez, 1995.

LUKÁCS, György. Por uma ontologia do ser social I. São Paulo: Boitempo, 2012.

LUKÁCS, György. Por uma ontologia do ser social II. São Paulo: Boitempo, 2013.

LUKÁCS, György. Prolegômenos para uma ontologia do ser social. São Paulo: Boitempo, 2010 .

MÁRKUS, György. Marxismo e antropologia: o conceito de "essência humana" na filosofia de Marx. São Paulo: Expressão Popular, 2015.

MARX, Karl. Cadernos de Paris \& Manuscritos econômico-filosóficos de 1844. São Paulo: Expressão Popular, 2015.

MARX, Karl.; ENGELS, Friedrich. A ideologia Alemã. São Paulo: Boitempo, 2007.

MARX, Karl.; ENGELS, Friedrich. O capital: crítica da economia política: Livro I: o processo de produção do capital. São Paulo: Boitempo, 2013.

MÉSZÁROS, István. Para além do capital: rumo a uma teoria da transição. São Paulo/Campinas: Boitempo Editorial/Editora da Unicamp, 2002.

NÓVOA, António. Prefácio. In.: Avaliar para aprender: fundamentos, práticas e políticas. Domingos Fernandes. São Paulo: Editora UNESP, 2009.

PEREIRA, Maria Eliza M.; MARINOTTI, Miriam; LUNA, Sérgio V. de. O compromisso do professor com a aprendizagem do aluno. In: HÜBNER, Maria Martha C.; MARINOTTI, Miriam. Análise do comportamento para a educação: contribuições recentes. Santo André, SP: ESETec Editores Associados, 2004.

PIAGET, Jean. Para onde vai a educação? 15. ed. Rio de Janeiro: José Olympio, 2000.

\begin{tabular}{|c|c|c|c|c|}
\hline Q Rovista Dialectus & Ano 9 & n. 16 & Janeiro - Abril 2020 & p. $82-99$ \\
\hline
\end{tabular}


TONET, Ivo. Educação, Cidadania e Emancipação Humana. 2. ed. Maceió: EDUFAL, 2013.

ZANARDINE, J. B. Ontologia e Avaliação da Educação Básica no Brasil (1990-2007). 2008. 208f. Tese (Doutorado em Educação) - Programa de Pós-Graduação em Educação, Universidade Federal de Santa Catarina, Florianópolis, 2008.

\begin{tabular}{|l|l|l|l|l|}
\hline Qevista Dialectus & Ano 9 & n. 16 & Janeiro - Abril 2020 & p. 82 - 99 \\
\hline
\end{tabular}

